\title{
Undiagnosed HIV, hepatitis B, and hepatitis $C$ infections in people with severe psychiatric disorders in Ethiopia
}

Getinet Ayano ${ }^{1,2^{*}}$ D, Kibrom Haile ${ }^{1}$, Abel Tesfaye ${ }^{1,3}$, Kelemua Haile $^{1}$, Sileshi Demelash ${ }^{4}$, Mikias Tulu', Belachew Tsegaye ${ }^{1}$, Melat Solomon ${ }^{1}$, Alem Kebede ${ }^{1}$, Aynalem Biru${ }^{1}$, Habte Birhanu', Gebresilassie Zenawi ${ }^{1}$, Yodit Habtamu', Esias Kibron', Seneshet Eshetu', Meseret Sefiw', Dawit Assefa' and Zegeye Yohannes ${ }^{1}$

\begin{abstract}
Background: Worldwide, there is limited epidemiologic evidence on the seroprevalence of undiagnosed chronic viral infections including HIV, hepatitis B virus (HBV) and hepatitis C virus ( $\mathrm{HCV}$ ) infections among patients with severe psychiatric disorders. To our knowledge, this is the first study to explore and compare undiagnosed seroprevalence rates of HIV, HBV, and HCV infections among patients with severe psychiatric disorders.

Method: In this study, we included a random sample of 309 patients with severe psychiatric disorders selected by systematic sampling technique. We used a structured clinical interview for DSM-IV (SCID) to confirm the diagnosis of severe psychiatric disorders among the participants. Binary and multivariable logistic regression models, adjusting for the potential confounding factors was used to explore the potential determinants of chronic viral infections.

Result: The prevalence estimates of HIV infection among patients with severe psychiatric disorders in this study (3.24\%) was roughly 3 times the estimated population prevalence of HIV infection in Ethiopia (1.1\%). This study showed that the prevalence rates of HBV and HCV infections among patients with severe psychiatric disorders were 4.85 and 1.29\%, respectively. Our results also showed that among patients with chronic viral infections, HIV, HBV and $\mathrm{HCV}, 76.92,60,80$, and $75 \%$ respectively were undiagnosed. Regarding associated factors, the presence of chronic viral infection was found to be significantly associated with the age of the participants (ranging between 30 and 40 years) after adjusting for the possible confounding factors [AOR $=3.95$ (95\%Cl.18-13.17)].

Conclusion: Even though the prevalence estimates of HIV (3.24\%), HBV (4.85\%), and HCV (1.29\%) infections were high among patients with severe psychiatric disorders, the majority of them remained undiagnosed. HBV was found to be the commonly undiagnosed infection (4 out of 5) followed by HCV (3 out of 4) and HIV (6 out of 10). The present study provided evidence of a significant association between the age of the participant (between 30 and 40 years) and chronic viral infections in patients with severe psychiatric disorders. Increasing the awareness of psychiatry professionals and early screening, as well as interventions of chronic viral infections among patients with severe psychiatric disorders are imperative.
\end{abstract}

Keywords: Severe psychiatric disorder, Undiagnosed, HIV infection, HBV infection, And HCV infection

\footnotetext{
* Correspondence: babiget2015@gmail.com

${ }^{1}$ Research and Training Department, Amanuel Mental Specialized Hospital, PO Box 171, Addis Ababa, Ethiopia

${ }^{2}$ School of Public Health, Curtin University, Perth, Westen Australia, Australia

Full list of author information is available at the end of the article
}

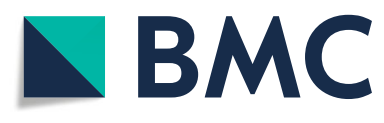

(c) The Author(s). 2020 Open Access This article is licensed under a Creative Commons Attribution 4.0 International License, which permits use, sharing, adaptation, distribution and reproduction in any medium or format, as long as you give appropriate credit to the original author(s) and the source, provide a link to the Creative Commons licence, and indicate if changes were made. The images or other third party material in this article are included in the article's Creative Commons licence, unless indicated otherwise in a credit line to the material. If material is not included in the article's Creative Commons licence and your intended use is not permitted by statutory regulation or exceeds the permitted use, you will need to obtain permission directly from the copyright holder. To view a copy of this licence, visit http://creativecommons.org/licenses/by/4.0/ The Creative Commons Public Domain Dedication waiver (http://creativecommons.org/publicdomain/zero/1.0/) applies to the data made available in this article, unless otherwise stated in a credit line to the data. 


\section{Background}

Severe psychiatric disorders such as schizophrenia, bipolar, schizoaffective, and depressive disorders are important contributors to the global burden of disease and they are among the common leading causes of the global burden of morbidity and early deaths $[1,2]$. Severe mental disorders including schizophrenia and psychosis affect 1 to $2 \%$ of the general adult population [3]. The lifetime prevalence of Bipolar I disorders in Ethiopia was estimated to be $0.6 \%$ in males and $0.3 \%$ in females [4]. The reported lifetime prevalence estimate of schizophrenia in Ethiopia was 4.7/1000 [5] and it was $1.2 \%$ for a major depressive disorder [6].

Epidemiologic evidence shows that a considerable percentage of people with severe psychiatric disorders had comorbid viral infections such as human immunodeficiency virus infection (HIV) 6.2-29.10\% [7-10], hepatitis $\mathrm{B}$ virus (HBV) $7.45-47.5 \%$ [10-13], as well as hepatitis C virus (HCV) $6.2-29.8 \%[7,10,13,14]$ infections at some point in their lives. These prevalence estimates are considerably higher than the reported prevalence in the general population [15-18]. In Ethiopia, the estimated prevalence of HIV, HBV, and HCV were $0.66 \%$ [15], $6.3 \%$ [16], and 3\% [16] respectively.

Scientific studies also showed that a large number of patients with HIV, HBV, as well as HCV infections in the general population remained undiagnosed $[19,20]$. For example, in a study performed in Europe, the estimated magnitude of undiagnosed HIV in the general population was $30 \%$ [19]. In another study conducted in the USA, about 40 to $50 \%$ of cases of $\mathrm{HCV}$ remain undiagnosed [21]. Regarding undiagnosed rates of HBV, the reported estimate of the prevalence of undiagnosed cases of HBV infection in the general population in a study conducted England was found to be 16\% [22].

Even though there are not enough supportive data on the prevalence estimate of undiagnosed viral infections among people with severe psychiatric disorders, it is assumed that the prevalence rates of undiagnosed HIV, HBV, and $\mathrm{HCV}$ believed to be considerably higher in patients with severe psychiatric disorders as compared to general population rates due to the nature of the illness which impairs their decision-making capacity [23, 24], makes them to involve in risky sexual behaviors $[25,26]$, and the reported higher magnitude of undiagnosed medical conditions (up to $80 \%$ ) in people with mental illness [27, 28].

In the context of the above issues, this study aimed to estimate the prevalence of undiagnosed chronic viral infections including HIV, HBV, and HCV infections among patients with severe psychiatric disorders. Since this is the first study that aimed to explore the prevalence estimates of undiagnosed HIV, HBV, and HCV infections among patients with severe psychiatric disorders, the findings of the study will help to better understand the prevalence rates of undiagnosed $\mathrm{HIV}, \mathrm{HBV}$, and $\mathrm{HCV}$ infections among patients with severe psychiatric disorders and to provide possible recommendations based on the findings.

\section{Methods \\ Study design}

A cross-sectional seroepidemiological survey was conducted among patients with severe psychiatric disorders recruited from the outpatient clinic at Amanuel Mental Specialized Hospital, Addis Ababa, Ethiopia from May 1, 2017, to July 30, 2017.

\section{Eligibility criteria}

To be included in this study the participant had to satisfy the following criteria: first, being an adult (aged over 18 years); second, had a diagnosis of one of the severe psychiatric disorders such as schizophrenia, bipolar, schizoaffective, and depressive disorders by the structured clinical interview for DSM- IV-TR axis I disorders (SCID) criteria. Additionally, for those randomly selected participants, the data collectors assessed the capacity of a person to consent to participate in the study. If the person had a capacity and given informed consent, they were considered eligible and further assessment was administered by the data collectors.

\section{Sampling procedure}

The present study is the part of comorbidity study in a specialized psychiatric setting in Ethiopia. Thus, the sample size was calculated using Epi-info version 7 with a $95 \% \mathrm{CI}, 5 \%$ margin of error and taking the prevalence of the comorbid medical disease in people with severe psychiatric disorders nearly $80 \%[28,29]$ and based on this the estimated sample size was 246 . Considering a $30 \%$ non-response rate a total sample of 320 patients with severe psychiatric disorders were included.

A systematic random sampling technique was employed to select the study participants. We identified the sampling interval by dividing the total patients with severe psychiatric disorders who had the treatment and follow up during the data collection period by total sample size which was 11 . We used a lottery method to select the first participant, and the remaining participants were selected at a regular interval as suggested by the systematic sampling method.

Those participants who have been randomly selected to be part of the survey but who refused to take part in the study were considered non-respondents. The non-response rate in the current study was found to be $3.44 \%$. (See Fig. 1).

\section{Measures}

\section{Screening for severe psychiatric disorders}

In this study, severe psychiatric disorders were assessed by using the structured clinical interview for DSM- IV- 


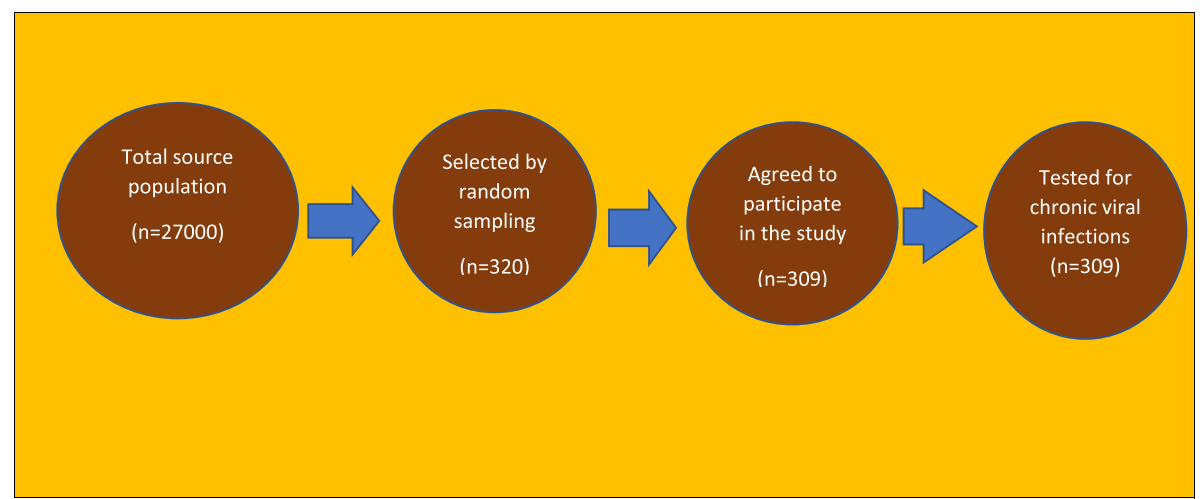

Fig. 1 Schematic representation of sample size and sampling procedure

TR axis I disorders (SCID) [30]. SCID which is a validated and standard diagnostic tool to assess DSM-IVaxis I disorders (major psychiatric disorders) and it has been extensively utilized to assess psychiatric disorders in previous studies in Ethiopia [31-35].

\section{Screening for HIV, HBV, and HCV infections}

The previous diagnosis of HIV, HBV, as well as HCV infections, were taken from the chart record of each participant. To do this we included a questionnaire assessing whether or not the participants had received a diagnosis of HIV, $\mathrm{HBV}$, as well as HCV infections from their chart record. The screening of the current HIV, HBV, as well as HCV infections was conducted by trained laboratory professionals after thorough interview and taking the willingness of the patients to participate. Five milliliters of the blood sample was aseptically collected from each participant by medical laboratory professionals. The samples were then tested for antibody to Hepatitis C virus (anti-HCV) and Hepatitis B antigen (HBsAg) using a rapid immunoassay designed to test HBV markers (HBsAg) [36, 37] for the diagnosis of $\mathrm{HCV}$ and $\mathrm{HBV}$ infection, respectively. From each collected samples anti-HCV and HBsAg were tested by using an enzyme-linked immunological assay (ELSA) following manufacturers protocol [37, 38]. Similarly, we screened for HIV diagnosis by using a rapid HIV diagnostic test kits according to the manufacturer's protocol $[39,40]$. We also adhered the national guide for conducting an HIV test in Ethiopia [40]. The Ethiopian ministry of health currently recommends the serial rapid testing algorithm with determine, STAT-PAK, and Uni-gold for the diagnosis of HIV infection [40]. All serum samples were tested for HIV $(1+2)$ antibody using the standard operating procedure (SOP) for HIV 1/2 STAT- PAK test in Ethiopia [40, 41]. All testing was conducted by qualified and experienced laboratory professionals.

The patients with no previous diagnosis but who received current positive tests for HIV, HBV, as well as HCV infections, were linked to the medical department which gives basic medical services including HIV testing, counseling, and treatment as well as care and treatment for the other medical conditions to handle the current diagnosis.

\section{Sociodemographic and other factors}

For this study, the sociodemographic and clinical characteristics such as age, sex, residence, marital status, educational status, ethnicity, religion, suicide, duration of the illness, history of relapse and hospitalizations were collected from each of the participants. All data was collected using trained assessors (masters level psychiatry professionals) assigned to evaluate the participants based on SCID criteria.

\section{Data quality control}

In the current study, to assure the quality of the data, the data collector (psychiatry professionals) who have adequate knowledge and experience about DSM- IV-TR were recruited. Additionally, training was delivered on how to complete the questionnaire, sampling procedure, inclusion criteria, ethical consideration, data collection procedure as well as the details of SCID for the data collectors and supervisors. The questionnaire was pretested before the actual data collection and the necessary modification was made. Two Supervisors followed the data collectors and the necessary correction was undertaken when needed. The collected data were reviewed and checked for completeness and relevance by the supervisor and principal investigator each day.

\section{Statistical analysis}

Stata version 14 software package was used to conduct statistical analysis. Frequency/percentage was used to express categorical variables and mean (standards deviations) was used for continues variables. We carried out bivariate and multivariate logistic regression to look at the association between outcome and explanatory variables. OR with $95 \%$ CI was used to measure the strength of the association and a $P$-value less than 0.05 was considered as statistically significant. 


\section{Ethical consideration}

In accordance with the given roles and national research ethics guidelines [42], the human research and ethics committee (HREC) of Amanuel Mental Specialized Hospital (Research and training department) reviewed and approved the study protocol. Participants who had the capacity to consent were involved in the study. Every participant signed a written consent after a clear and detailed explanation of the purpose, objectives, significance, benefits, and harms of participation, as well as confidentiality of the collected information to each of the study participants. The survey teams (coordinators and investigators) made sure that the anonymity and confidentiality of the participant included in this serologic study were confirmed.

\section{Results}

Sociodemographic characteristics of the participants

Table 1 shows the sociodemographic characteristics of the participant included in this study. A total of 309 participants with severe psychiatric disorders including schizophrenia $(n==135)$, schizoaffective $(n=28)$, bipolar $(n=54)$, and depressive $(n=92)$ disorders were involved in the current study, yielding a response rate $96.56 \%$. The mean (SD) age and duration of the participants were 36.19 (10.45) and 10.04 (8.66) years, respectively. Nearly two-thirds of the participants 202 (65.37\%) were males, 202 (65.37\%) were single, 118 (38.19\%) attended secondary school, nearly half 157 (51.47\%) were Orthodox Christians, and the majority of the participants 235 (76.05\%) were from urban areas.

The prevalence of chronic viral infections in patients with severe psychiatric disorders

In the current study, the overall prevalence of chronic viral infections (includes the three blood born viruses HIV, HBV, and HCV combined) was found to be $8.41 \%$ (95\%CI 5.74-12.06).

Regarding the specific types of viral infections, the prevalence of HIV, HBV, and HCV among people with SPD were found to be $3.24 \%$ (95\%CI $1.74-5.93), 4.85 \%$ (95\% CI 2.94-7.92), and $1.29 \%$ (95\%CI $0.48-3.42)$, respectively.

Moreover, in this study, the prevalence of any hepatitis virus (HBV and HCV combined) was found to be $5.83 \%$. Also, we found similar prevalence estimates for the coinfection of HIV and HBV (0.32\%), HBV and HCV (0.32\%), as well as HIV and HCV (0.32\%). The magnitude of the triple infection (HIV, $\mathrm{HBV}$, and $\mathrm{HCV}$ on the same person) in this study was found to be $0.00 \%$ (Table 2).

The prevalence of undiagnosed chronic viral infections in patients with severe psychiatric disorders

In this study, the prevalence of the undiagnosed chronic viral infections among patients with severe psychiatric disorders was $6.47 \%$ from the total participants and
Table 1 Sociodemographic characteristics of the participants with severe psychiatric disorders in Addis Ababa, Ethiopia ( $n=$ 309)

\begin{tabular}{|c|c|c|}
\hline Characteristics & Frequency & Percentage \\
\hline \multicolumn{3}{|l|}{ Age } \\
\hline 30 or less & 110 & 35.60 \\
\hline 30 to 40 & 106 & 34.30 \\
\hline 41 and more & 93 & 30.10 \\
\hline \multicolumn{3}{|l|}{ Sex } \\
\hline Male & 202 & 65.37 \\
\hline Female & 107 & 34.63 \\
\hline \multicolumn{3}{|l|}{ Educational status } \\
\hline Uneducated & 30 & 9.71 \\
\hline Primary & 103 & 33.33 \\
\hline Secondary & 118 & 38.19 \\
\hline Higher & 58 & 18.77 \\
\hline \multicolumn{3}{|l|}{ Religion } \\
\hline Muslim & 87 & 28.16 \\
\hline Orthodox & 157 & 51.46 \\
\hline Protestant & 57 & 18.54 \\
\hline Others & 6 & 1.94 \\
\hline \multicolumn{3}{|l|}{ Ethnicity } \\
\hline Amhara & 95 & 30.74 \\
\hline Gurage & 82 & 26.54 \\
\hline Oromo & 91 & 29.45 \\
\hline Others & 41 & 13.27 \\
\hline \multicolumn{3}{|l|}{ Marital status } \\
\hline Single & 202 & 65.37 \\
\hline Married & 74 & 23.95 \\
\hline Divorcee/widowed & 33 & 10.68 \\
\hline \multicolumn{3}{|l|}{ Residence } \\
\hline Urban & 235 & 76.05 \\
\hline Rural & 74 & 29.95 \\
\hline \multicolumn{3}{|l|}{ SPD type } \\
\hline Schizophrenia & 135 & 43.69 \\
\hline Bipolar disorder & 54 & 17.48 \\
\hline MDD & 92 & 29.77 \\
\hline Schizoaffective disorders & 28 & 9.06 \\
\hline
\end{tabular}

among patients with chronic viral infections, 76.92\% were undiagnosed.

We found that four participants had undiagnosedcases of HIV (1.94\% of the total patients with severe psychiatric disorders and 60\% among HIV cases).

We also found that four participants had undiagnosedcases of HBV (3.88\%) of the total patients with severe psychiatric disorders and 80\% among HBV cases). 
Table 2 The prevalence of infectious diseases among patients with severe mental disorders in central Ethiopia, $n=309$

\begin{tabular}{llll}
\hline Illness & Cases & Prevalence (\%) & $95 \% \mathrm{Cl}$ \\
\hline Overall infectious disease & 26 & 8.41 & $5.78-12.06$ \\
HIV & 10 & 3.24 & $1.74-5.93$ \\
HBV & 15 & 4.85 & $2.94-7.92$ \\
HCV & 4 & 1.29 & $0.48-3.42$ \\
HBV or HCV & 18 & 5.83 & 3.699 .08 \\
$\quad$ HIV and HBV coinfection & 1 & 0.32 & $0.05-2.28$ \\
HIV and HCV coinfection & 1 & 0.32 & $0.05-2.28$ \\
HBV and HCV coinfection & 1 & 0.32 & $0.05-2.28$ \\
Triple infection & 0 & 0.00 & - \\
\hline
\end{tabular}

Key: HIV Human Immune Deficiency Virus, HIB Hepatitis B virus, HVC Hepatitis $C$ virus

Furthermore, four participants had undiagnosed-cases of $\mathrm{HCV}(0.97 \%)$ among the total patients with severe psychiatric disorders and $75 \%$ among $\mathrm{HCV}$ cases) (Table 3 and Fig. 2).

Factors associated with undiagnosed chronic viral infections in patients with severe psychiatric disorders

In this study, after adjusting the model for the possible confounding factors, the age of the participant was found to be a significant predictor of chronic viral infections. The odds of having chronic viral infections were increased by 3.95 $[A O D=3.95(95 \%$ CI.18-13.17) $]$ for those participants in the age range between 30 and 40 years as compared with the age group between 18 and 30 years (Table 4).

\section{Discussion}

\section{Main findings}

To the best of our knowledge, this is the first study that examined the epidemiology of undiagnosed chronic viral infections including $\mathrm{HIV}, \mathrm{HBV}$, and $\mathrm{HCV}$ among patients with severe psychiatric disorders. The main purpose of the study was to estimate the prevalence of undiagnosed chronic viral infections in patients with severe psychiatric disorders in a specialized psychiatric setting. The results of this study revealed that a remarkable proportion of people with severe psychiatric disorders had undiagnosed chronic viral infections and the estimated prevalence of undiagnosed HIV, $\mathrm{HBV}$ and $\mathrm{HCV}$ were considerably higher than the reported prevalence estimates in the general population. Among patients with chronic viral infections, HIV, HBV and HCV, 76.92, 60, 80 , and $75 \%$ respectively were undiagnosed. These findings suggest the urgent need to improve the awareness of psychiatry professionals as well as early screening and management of chronic viral infections among patients with severe psychiatric disorders.

\section{The prevalence of chronic viral infections in people with severe psychiatric disorders}

In this study, the prevalence of chronic viral infections such as HIV, HBV, and HCV was considerably lower than the reported global magnitude of those viral diseases among patients with severe psychiatric disorders from previously published studies [10, 43, 44]. For example, a recent meta-analysis showed that the prevalence of HIV, HBV, and HCV among people with severe psychiatric disorders was 7.59, 15.3, and 7.21\% [10], respectively which is significantly higher than the reported prevalence of HIV (3.2\%), HBV (4.85\%) as well as HCV (1.29\%) in this study. As compared with the findings of other countries the prevalence of HIV was in this study was consistent with the magnitude of HIV among people with severe mental illness in central and South America (2.74\%) [43] but lower than the reported magnitude of HIV in Africa (19.2\%) [43] and North America (6.0\%) [43]. In contrast, our findings are lower than the metaanalysis reports of the magnitude of HIV among people with severe mental illness in Europe (1.9\%) [43] and Asia (1.5\%) [43]. However, the prevalence of HBV and HCV in this study were consistent with the reported magnitude of HBV and HCV from the developing countries but considerably lower than the magnitude of $\mathrm{HBV}$ and $\mathrm{HCV}$ from the developed countries [10, 43]. The possible reasons for the lower magnitude of $\mathrm{HBV}, \mathrm{HBV}$ and $\mathrm{HCV}$ from the reported global as well as developed countries could be due to the higher magnitude of injectable drug uses (IDU) in developed countries as compared with developing countries including Ethiopia which is the major causes for blood born virus (BBVs) such as HIV, hepatitis B and $C$ viruses.

The estimated prevalence of the coinfection of HIV and $\mathrm{HBV}(0.32 \%), \mathrm{HBV}$ and $\mathrm{HCV}(0.32 \%)$, as well as

Table 3 The prevalence of undiagnosed infectious diseases among patients with severe mental disorders in central Ethiopia, $n=$ 309

\begin{tabular}{lllll}
\hline Illness & Chart diagnosis, $\mathrm{n}(\%)$ & Real diagnosis, $\mathrm{n}(\%)$ & Undiagnosed illness from the total, $\mathrm{n}(\%)$ & Undiagnosed illness from the cases, $\mathrm{n}(\%)$ \\
\hline $\begin{array}{l}\text { Overall infectious } \\
\text { disease }\end{array}$ & $7(2.77 \%)$ & $26(8.41)$ & $20(6.47)$ & $20(76.92)$ \\
HIV & $4(1.29)$ & $10(3.24)$ & $6(1.94 \%)$ & $6(60.00)$ \\
HBV & $3(0.97)$ & $15(4.85)$ & $12(3.88)$ & $12(80.00)$ \\
HCV & $1(0.32)$ & $4(1.29)$ & $3(0.97)$ & $3(75.00)$ \\
\hline
\end{tabular}

Key: HIV Human Immune Deficiency Virus, HIB Hepatitis B virus, HVC Hepatitis C virus 


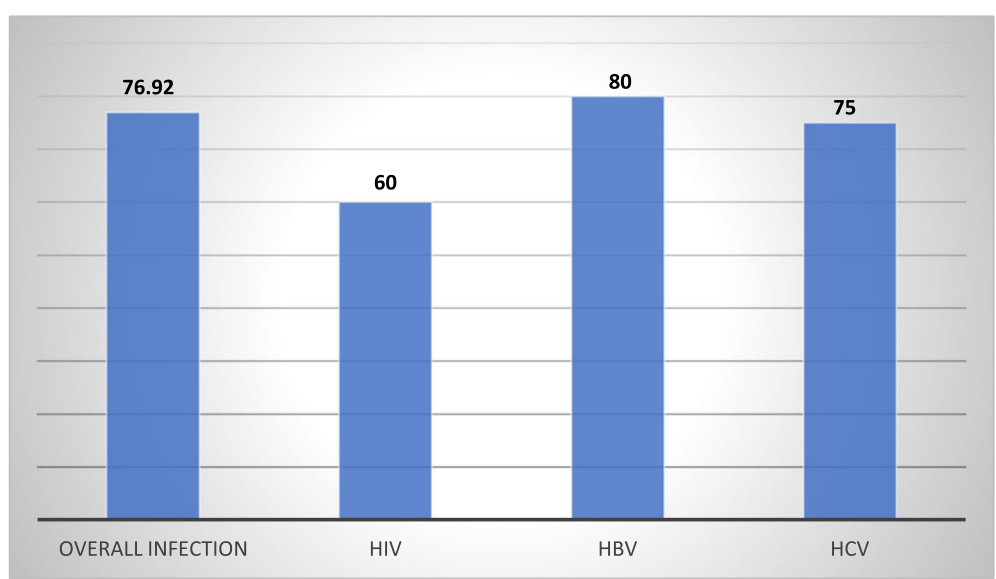

Fig. 2 The rates of misdiagnosis of infectious diseases (in percenatge)

Table 4 Factors associated with infectious disease in people with severe mental disorders, Addis Ababa, Ethiopia

\begin{tabular}{|c|c|c|c|c|}
\hline \multirow[t]{2}{*}{ Characteristics } & \multicolumn{2}{|c|}{ Misdiagnosis } & \multirow{2}{*}{$\begin{array}{l}\text { Crude odds } \\
\text { ratio }(95 \% \mathrm{Cl})\end{array}$} & \multirow{2}{*}{$\begin{array}{l}\text { Adjusted odds } \\
\text { ratio }(95 \% \mathrm{Cl})\end{array}$} \\
\hline & Yes & No & & \\
\hline \multicolumn{5}{|l|}{ Gender } \\
\hline Female & 13 & 94 & $2.01(0.89-4.50)$ & $1.98(0.83-4.76)$ \\
\hline Male & 13 & 189 & 1 & 1 \\
\hline \multicolumn{5}{|l|}{ Age } \\
\hline $18-30$ & 4 & 106 & 1 & 1 \\
\hline $31-40$ & 14 & 92 & $4.03(1.28-12,68)^{*}$ & $3.95(1.18-13.17)^{*}$ \\
\hline$\geq 40$ & 8 & 85 & $2.49(0.72-8.56)$ & $1.17(0.58-2.36)$ \\
\hline \multicolumn{5}{|l|}{ Residence } \\
\hline Rural & 3 & 71 & 1 & 1 \\
\hline Urban & 23 & 212 & $2.56(0.75-8.80)$ & $0.38(0.10-1.45)$ \\
\hline \multicolumn{5}{|l|}{ Marital status } \\
\hline Single & 12 & 190 & 1 & 1 \\
\hline Married & 8 & 66 & $1.91(0.75-4.90)$ & $2.39(0.86-6.49)$ \\
\hline Divorce/widowed & 6 & 27 & $3.51(1.22-10.15)^{*}$ & $2.58(0.80-8.33)$ \\
\hline \multicolumn{5}{|c|}{ Misdiagnosed severe psychiatric disorder } \\
\hline Correct diagnosis & 14 & 174 & - & - \\
\hline Misdiagnosis & 12 & 109 & $1.37(0.61-3.06)$ & $1.79(0.74-2.07)$ \\
\hline \multicolumn{5}{|l|}{ Relapse } \\
\hline Relapsed & 19 & 207 & $1.00(0.40-2.45)$ & $0.77(0.28-2.11)$ \\
\hline No relapse & 7 & 76 & 1 & \\
\hline \multicolumn{5}{|l|}{ Admission } \\
\hline Admission & 15 & 181 & $0.77(0.34-1.74)$ & $0.83(0.33-2.06)$ \\
\hline No admission & 11 & 102 & 1 & 1 \\
\hline WHODAS score & & & $0.87(0.38-1.97)$ & $0.86(0.36-2.03)$ \\
\hline
\end{tabular}

* Significant association ( $p$-value $<0.05$ ) 
HIV and HCV (0.32\%) in this study, were consistent with the reported magnitude of coinfection from a recent systematic review $[45,46]$. However, the magnitude of the triple infection in this study $(0.00 \%)$ was different from the reported magnitude of the global magnitude of triple infection $1.29 \%[45,46]$. The lower number of participants as compared with the above studies could be the possible reason for the observed variation because of the rare nature of the occurrence of triple infection requiring the large sample size to estimate the magnitude.

Regarding associated factors, consistent with previous epidemiologic studies [47], the findings of this study demonstrated that the odds of having chronic viral infections was 3.95 times greater $[\mathrm{AOR}=3.95(95 \% \mathrm{CI} 1.18-$ 13.17)] for those patients with severe mental illness in the age range between 30 and 40 years.

\section{The prevalence of undiagnosed chronic viral infections in people with severe psychiatric disorders}

In this study, 20 participants had undiagnosed infected disease in patients with severe psychiatric disorders with a prevalence of $6.47 \%$ from the total participants and $76.92 \%$ of those participants with infectious disease. The rate of undiagnosed disease was relatively higher for the hepatitis B virus ( $80 \%$ of $\mathrm{HBV}$ cases) followed by hepatitis C (75\% of HCV cases) and HIV (60\% of HIV cases). We found that the rates of undiagnosed $\mathrm{HCV}, \mathrm{HBV}$, as well as $\mathrm{HCV}$ in this study, was remarkably higher as compared with the estimated undiagnosed rates of $\mathrm{HCV}, \mathrm{HBV}$, and $\mathrm{HCV}$ from the general population [19, 47]. Supporting this view a study conducted in Europe showed that the prevalence of undiagnosed HIV in the general population was 30\% which is remarkably higher than the findings of the estimated prevalence undiagnosed HIV cases in this study (60\%) [19]. Another study conducted in France revealed the prevalence of undiagnosed HIV infection in the general population to be $0.065 \%$ [48]. Similarly to HIV infection epidemiologic studies also revealed that the magnitude of 40 to $50 \%$ cases of HCV remain undiagnosed in the USA [21] whereas the reported estimate of the prevalence of undiagnosed cases of HBV infection in general population in a study conducted England was found to be 16\% [22] which is remarkably lower than the results of this study where about $80 \%$ of those patients having HBV infections remained undiagnosed in people with severe mental illness.

\section{Suggestions for future research and clinical practice}

The current study had some suggestions for future research as well as clinical practice. First, this study shows that the undiagnosed cases of chronic viral infections are remarkably higher in patients with severe psychiatric disorders. However, the data for specific categories of severe psychiatric disorders are not analyzed due to a small number of participants for the specific disorder, which suggests the need for future studies addressing these issues. Second, the prevalence of undiagnosed chronic viral infections is very high as compared with general pollution estimates which need future robust the possible reasons for the highest magnitude. Thirdly, increasing awareness using educational programs tailored to chronic viral infections among patients with severe mental illness to the patients and general public is recommended; fourthly, attention need to be given to possibly reduce the extensive level of undiagnosed viral infections among patients with severe mental illness by the concerned body with the possibilities of implementing continues medical education (CME) so that the patients will be safe from suffering related to short term and long term impacts of the undiagnosed infection-causing strong, cirrhosis and other physical and mental health-related problems; Fifthly, possible screening programs patients with severe mental illness particularly for those patients who are in high risks (young, sexually active and substance users). Furthermore, government need to have a plan aimed to early detection and interventions of HIV, HBV, and HCV infections in patients with severe mental illness; finally, studies focusing on best screening strategies to allow earlier diagnosis and treatments of HIV, HBV, and HCV infections in patients with severe mental illness who are unaware of their infection status are warranted.

\section{Strengths and limitations}

This study had several strengths: (1) to our knowledge, this is the first study to estimate and compare the level of undiagnosed chronic viral infections including HIV, HBV, and HCV infections in patients with severe mental illness; (2) the use of standard and diagnostic instrument (SCID) to confirm the severe psychiatric disorders. Nevertheless, the current study had also some limitations: first, due to the cross-sectional nature of the study factors associated with misdiagnosis may not imply causality. Secondly, past diagnosis (previous diagnosis) was taken from the chart of the patients where there are possibilities of not recording or missing previous records which underestimate the diagnosed cases. Lastly, the small number of samples needs to be considered in interpreting the findings, particularly for the prevalence co-occurrence of chronic viral infections (the true prevalence estimates might be underestimated due to the small samples).

\section{Conclusion}

To sum up, the current study revealed that a considerable percentage of people with severe psychiatric disorders had a diagnosis of HIV (3.24\%), HBV (4.85\%), HCV (1.29\%), and overall viral $(8.41 \%)$ infections. In this study, HBV was found to be the commonly undiagnosed viral infection (80\%) followed by HCV (75\%) and HIV (60\%) infections. The age range between 30 and 40 years was found to be a 
significant predictor of chronic viral infections among patients with severe psychiatric disorders.

Early screening and treatment of HIV, HBV, as well as $\mathrm{HCV}$ infection, are warranted among patients with severe psychiatric disorders. Additionally, strong epidemiologic studies evaluating the reasons for the highest level of undiagnosed infectious disease among patients with SPD are recommended. Finally, Continues medical education (CME), as well as supplementary refreshment training on chronic viral infections, are suggested for the psychiatry professionals.

\section{Abbreviations}

AOR: Adjusted Odds Ratio; Cl: Confidence Interval; CME: Continues Medical Education; DSM: Diagnostic and Statistical Manual of Mental Disorders; ELSA: Enzyme-Linked Immunological Assay; HBsAg: Hepatitis B Suraface Antigen; HIB: Hepatitis B Virus; HIV: Human Immune Deficiency Virus; HREC: Human Research and Ethics Committee; HVC: Hepatitis C Virus; IDU: Injectable Drug Use; OR: Odds Ratio; SCID-I: Structured Clinical Interview for DSM-IV axis I Disorders; SOP: Standard Operating Procedure; SPD: Severe Psychiatric Disorders; USA: United States of America

\section{Acknowledgments}

We are grateful to Amanuel Mental Specialized Hospital for funding the study and the HREC of the hospital research and training department for their ethical evaluation and approval. We are also very grateful to the study participants for their cooperation in providing the necessary information and giving us their precious time.

\section{Authors' contributions}

GA Conceptualized the study and was involved in the study design, reviewed the article, analysis, report writing, discussion, and drafted the manuscript. DA, KH1, KH2, AT, ZY, MT, and SD were involved in the study design, data entry, and review of the subsequent drafts. MS, ZR, AK, GH, HB, $G Z, A T, M A, A B, M S, E K, S E, Y H, B T$, and ES were involved in the discussion of the overall document, and review of subsequent drafts. All authors read and approved the final manuscript.

\section{Funding}

This research work is funded by Amanuel mental specialized Hospital, Addis, Ababa, Ethiopia.

\section{Availability of data and materials}

The datasets used and analyzed during the current study are not publically available due to ethical restriction and personal data protections but are available from the corresponding author on reasonable request.

\section{Ethics approval and consent to participate}

The human research and ethics committee (HREC) of Amanuel Mental Specialized Hospital (Research and training department) reviewed and approved the study in accordance with the given roles and national research ethics guideline. Confidentiality and privacy were maintained at all levels of the survey. Informed written consent was obtained from each study participant. The right to withdraw from the research process at any point in time was respected. Privacy and strict confidentiality were maintained during the interview process.

\section{Consent for publication}

Not applicable.

\section{Competing interests}

The authors declare that they have no competing interests.

\section{Author details}

${ }^{1}$ Research and Training Department, Amanuel Mental Specialized Hospital, PO Box 171, Addis Ababa, Ethiopia. ${ }^{2}$ School of Public Health, Curtin University, Perth, Westen Australia, Australia. ${ }^{3}$ Department of medicine,
Hawassa University, Hawassa, Ethiopia. ${ }^{4}$ Ethiopian public health institute, Addis Ababa, Ethiopia.

Received: 4 July 2019 Accepted: 19 February 2020

Published online: 27 February 2020

\section{References}

1. Murray CJ, Lopez AD. Global mortality, disability, and the contribution of risk factors: Global Burden of Disease Study. Lancet (London, England). 1997; 349(9063):1436-42.

2. Murray CJ, Vos T, Lozano R, Naghavi M, Flaxman AD, Michaud C, Ezzati M, Shibuya K, Salomon JA, Abdalla S, et al. Disability-adjusted life years (DALYS) for 291 diseases and injuries in 21 regions, 1990-2010: a systematic analysis for the global burden of disease study 2010. Lancet. 2012;380(9859):2197-223.

3. National Collaborating Centre for Mental H: National Institute for Health and Clinical Excellence: Guidance. Psychosis and Schizophrenia in Adults: Treatment and Management: Updated Edition 2014. edn, vol. 2014. London: National Institute for Health and Care Excellence (UK); National Collaborating Centre for Mental Health; 2014.

4. Negash A, Alem A, Kebede D, Deyessa N, Shibre T, Kullgren G. Prevalence and clinical characteristics of bipolar I disorder in Butajira, Ethiopia: a community-based study. J Affect Disord. 2005:87(2):193-201.

5. Kebede D, Alem A, Shibre T, Negash A, Fekadu A, Fekadu D, Deyassa N, Jacobsson L, Kullgren G. Onset and clinical course of schizophrenia in Butajira-Ethiopia--a community-based study. Soc Psychiatry Psychiatr Epidemiol. 2003:38(11):625-31.

6. Mogga S, Prince M, Alem A, Kebede D, Stewart R, Glozier N, Hotopf M. Outcome of major depression in Ethiopia: population-based study. $\mathrm{Br}$ J Psychiatry. 2006;189(3):241-6.

7. Klinkenberg WD, Caslyn RJ, Morse GA, Yonker RD, McCudden S, Ketema F, Constantine NT. Prevalence of human immunodeficiency virus, hepatitis B, and hepatitis $C$ among homeless persons with co-occurring severe mental illness and substance use disorders. Compr Psychiatry. 2003:44(4):293-302.

8. Hung C-C, Loh E-W, Hu T-M, Chiu H-J, Hsieh H-C, Chan C-H, Lan T-H. Prevalence of hepatitis $B$ and hepatitis $C$ in patients with chronic schizophrenia living in institutions. J Chin Med Assoc. 2012;75(6):275-80.

9. Singh D, Berkman A, Bresnahan M. Seroprevalence and HIV-associated factors among adults with severe mental illness: a vulnerable population. SAMJ. 2009:99(7):523-7.

10. Ayano G, Tulu M, Haile K, Assefa D, Habtamu Y, Araya G, Yohannis Z. A systematic review and meta-analysis of gender difference in epidemiology of HIV, hepatitis B, and hepatitis C infections in people with severe mental illness. Ann General Psychiatry. 2018;17(1):16.

11. Said W, Saleh R, Jumaian N. Prevalence of hepatitis B virus among chronic schizophrenia patients; 2001.

12. Di Nardo V, Petrosillo N, Ippolito G, Bonaventura ME, Puro V, Chiaretti B, Tosoni M. Prevalence and incidence of hepatitis B virus, hepatitis $C$ virus and human immunodeficiency virus among personnel and patients of a psychiatric hospital. Eur J Epidemiol. 1995;11(2):239-42.

13. Rosenberg SD, Drake RE, Brunette MF, Wolford GL, Marsh BJ. Hepatitis C virus and HIV co-infection in people with severe mental illness and substance use disorders. Aids. 2005;19:S26-33.

14. Lagios K, Deane FP. Severe mental illness is a new risk marker for bloodborne viruses and sexually transmitted infections. Aust N Z J Public Health. 2007:31(6):562-6.

15. Deribew A, Biadgilign S, Deribe K, Dejene T, Tessema GA, Melaku YA, Lakew Y, Amare AT, Bekele T, Abera SF, et al. The burden of HIV/AIDS in Ethiopia from 1990 to 2016: evidence from the global burden of diseases 2016 study. Ethiop J Health Sci. 2019:29(1):859-68.

16. Belyhun Y, Maier M, Mulu A, Diro E, Liebert UG. Hepatitis viruses in Ethiopia: a systematic review and meta-analysis. BMC Infect Dis. 2016;16(1):761.

17. Frank TD, Carter A, Jahagirdar D, Biehl MH, Douwes-Schultz D, Larson SL, Arora M, Dwyer-Lindgren L, Steuben KM, Abbastabar H, Abu-Raddad LG. Global, regional, and national incidence, prevalence, and mortality of HIV, 1980-2017, and forecasts to 2030, for 195 countries and territories: a systematic analysis for the global burden of diseases, injuries, and risk factors study 2017. The lancet HIV. 2019;6(12):e831-59.

18. Yizengaw E, Getahun T, Geta M, Mulu W, Ashagrie M, Hailu D, Tedila S. Seroprevalence of hepatitis B virus infection and associated factors among health care workers and medical waste handlers in primary hospitals of north-West Ethiopia. BMC Res Notes. 2018;11(1):437. 
19. Hamers FF, Phillips AN. Diagnosed and undiagnosed HIV-infected populations in Europe. HIV Med. 2008;9(Suppl 2):6-12.

20. Reyes-Urueña JM, Campbell CNJ, Vives N, Esteve A, Ambrosioni J, Tural C, Ferrer E, Navarro G, Force L, García I, et al. Estimating the HIV undiagnosed population in Catalonia, Spain: descriptive and comparative data analysis to identify differences in MSM stratified by migrant and Spanish-born population. BMJ Open. 2018;8(2):e018533.

21. Wiessing L, Ferri M, Grady B, Kantzanou M, Sperle I, Cullen KJ, Hatzakis A, Prins M, Vickerman P, Lazarus JV. Hepatitis C virus infection epidemiology among people who inject drugs in Europe: a systematic review of data for scaling up treatment and prevention. PLoS One. 2014;9(7):e103345.

22. Mcpherson S, Valappil M, Moses S, Eltringham G, Miller C, Baxter K, Brown B, Clapper P, Chan A, Hudson M, et al. Undiagnosed chronic hepatitis B is prevalent in the british-chinese community of the north east (NE) of England. Gut. 2011;60(Suppl 1):A241.

23. Kim YT, Lee K-U, Lee SJ. Deficit in decision-making in chronic, stable schizophrenia: from a reward and punishment perspective. Psychiatry Investig. 2009;6(1):26-33.

24. Mason L, O'Sullivan N, Montaldi D, Bentall RP, El-Deredy W. Decision-making and trait impulsivity in bipolar disorder are associated with reduced prefrontal regulation of striatal reward valuation. Brain. 2014;137(Pt 8):2346-55.

25. Mwangi C, Karanja S, Gachohi J, Wanjihia V, Ngang'a Z. Depression, injecting drug use, and risky sexual behavior syndemic among women who inject drugs in Kenya: a cross-sectional survey. Harm Reduct J. 2019;16(1):35.

26. Lundberg $P$, Johansson E, Okello E, Allebeck $P$, Thorson A. Sexual risk behaviours and sexual abuse in persons with severe mental illness in Uganda: a qualitative study. PLoS One. 2012;7(1):e29748.

27. Ayano G. Comorbid medical and substance use disorders in persons with bipolar disorder. Int J Physical Med Rehabil. 2016.

28. Ayano G. Co-occurring medical and substance use disorders in patients with schizophrenia: a systematic review. Int J Ment Health. 2019;48(1):62-76.

29. de Hert M, Correll CU, Bobes J, Cetkovich-Bakmas M, Cohen D, Asai I, Detraux J, Gautam S, H-J M, Ndetei DM, et al. Physical illness in patients with severe mental disorders. I. Prevalence, impact of medications and disparities in health care. World Psychiatry. 2011;10(1):52-77.

30. First M, Spitzer R, Gibbon M, Williams J. Structured clinical interview for DSM-IV axis I disorders, clinician version (SCID-CV). Washington DC: American psychiatric press; 1997.

31. Ayano G, Assefa D, Haile K, Chaka A, Solomon H, Hagos P, Yohannis Z, Haile K, Bekana L, Agidew M, et al. Mental, neurologic, and substance use (MNS) disorders among street homeless people in Ethiopia. Ann General Psychiatry. 2017;16:40.

32. Duko B, Ayano G, Bekana L, Assefa D. Prevalence and correlates of cooccurring substance use disorder among patients with severe mental disorder at Amanuel mental specialized hospital, Addis Ababa, Ethiopia. J Neuropsychopharmacol Mental Health. 2015;1:101.

33. Duko B, Ayano G. Suicidal ideation and attempts among people with severe mental disorder, Addis Ababa, Ethiopia, comparative cross-sectional study. Ann General Psychiatry. 2018;17(1):23.

34. Fanta T, Bekele D, Ayano G. The prevalence and associated factors of depression among patients with schizophrenia in Addis Ababa, Ethiopia, cross-sectional study. BMC Psychiatry. 2020;20(1):3.

35. Ayano G, Duko B. Relapse and hospitalization in patients with schizophrenia and bipolar disorder at the St Amanuel mental specialized hospital, Addis Ababa, Ethiopia: a comparative quantitative cross-sectional study. Neuropsychiatr Dis Treat. 2017;13:1527-31.

36. Yazdani Y, Roohi A, Khoshnoodi J, Shokri F. Development of a sensitive enzyme-linked immunosorbent assay for detection of hepatitis B surface antigen using novel monoclonal antibodies. Avicenna J Med Biotechnol. 2010;2(4):207-14.

37. Xiang T, Jiang Z, Zheng J, Lo C, Tsou H, Ren G, Zhang J, Huang A, Lai G. A novel double antibody sandwich-lateral flow immunoassay for the rapid and simple detection of hepatitis C virus. Int J Mol Med. 2012;30(5):1041-7.

38. Lequin RM. Enzyme immunoassay (EIA)/enzyme-linked immunosorbent assay (ELISA). Clin Chem. 2005;51(12):2415-8.

39. CHEMBIO: Diagnostic System I: HIV 1/2 STAT-PAK ${ }^{\circledR}$ ASSAY: FG-60-9505-1-Rev2: 2016. http://chembio.com/wp-content/uploads/2018/10/10-6072-1Product-Insert-for-HIV-12-STAT-PAK-Assay-FG-60-9505-1-Rev-2.pdf.

40. $\mathrm{MOH}$. Guidelines for HIV counselling and testing in Ethiopia: 2007. https:// www.who.int/hiv/topics/vct/ETH_HCT_guidelinesJune26_clean.pdf.
41. Shanks L, Siddiqui MR, Kliescikova J, Pearce N, Ariti C, Muluneh L, Pirou E, Ritmeijer K, Masiga J, Abebe A. Evaluation of HIV testing algorithms in Ethiopia: the role of the tie-breaker algorithm and weakly reacting test lines in contributing to a high rate of false positive HIV diagnoses. BMC Infect Dis. 2015;15:39.

42. ESTC: The Ethiopian science and technology commission (ESTC): National Research Ethics Review Guideline 2014.

43. Hughes E, Bassi S, Gilbody S, Bland M, Martin F. Prevalence of HIV, hepatitis $B$, and hepatitis $C$ in people with severe mental illness: a systematic review and meta-analysis. Lancet Psychiatry. 2016;3(1):40-8.

44. Wainberg M, Dixon L. Ending HIV, hepatitis B, and hepatitis C: what about people with severe mental illness? Lancet Psychiatry. 2017;4(9):651-3.

45. Platt L, Easterbrook P, Gower E, McDonald B, Sabin K, McGowan C, Yanny I, Razavi H, Vickerman P. Prevalence and burden of HCV co-infection in people living with HIV: a global systematic review and meta-analysis. Lancet Infect Dis. 2016;16(7):797-808.

46. Desikan P, Khan Z. Prevalence of hepatitis B and hepatitis C virus Coinfection in India: a systematic review and meta-analysis. Indian J Med Microbiol. 2017:35(3):332-9.

47. Parés-Badell O, Espelt A, Folch C, Majó X, González V, Casabona J, Brugal MT Undiagnosed HIV and hepatitis C infection in people who inject drugs: from new evidence to better practice. J Subst Abus Treat. 2017;77:13-20.

48. Cazein F, Barin F, Le Strat Y, Pillonel J, Le Vu S, Lot F, Thierry D, Meffre C, Semaille $C$. Prevalence and characteristics of individuals with undiagnosed HIV infection in France: evidence from a survey on hepatitis B and C seroprevalence. J Acquir Immune Defic Syndr. 2012;60(4):e114-7.

\section{Publisher's Note}

Springer Nature remains neutral with regard to jurisdictional claims in published maps and institutional affiliations.

\section{Ready to submit your research? Choose BMC and benefit from:}

- fast, convenient online submission

- thorough peer review by experienced researchers in your field

- rapid publication on acceptance

- support for research data, including large and complex data types

- gold Open Access which fosters wider collaboration and increased citations

- maximum visibility for your research: over $100 \mathrm{M}$ website views per year

At BMC, research is always in progress.

Learn more biomedcentral.com/submissions 